\title{
A Survey on the Effects of Mal-traditional Practices Among Indigenous People in State of Benishangul Gumuz
}

\author{
Shewa Basizew \\ M.Ed in English as a Foreign Language
}

\author{
Abebe Ano \\ Assistant Professor of History and $\mathrm{PhD}$ candidate
}

Atnafu Morka

Assistant Professor in Geography and Environmental Study

\begin{abstract}
In today's Ethiopia where challenges on development is made by indigenous people in regions, State of Benishangul Gumuz region is extending its effort towards reaching excellence in all aspects including health and societal matters. As part of the country's effort, Benishangul Gumuz region in general and Assosa University in particular carries out various studies based on scientific plans for scaling up its achievements constantly. However, Mal-traditional practices (MTP's)-Festival Ceremony, marriage related practices (early marriage, Abduction marriage, Bride wealth payment and inheritance marriage), domestic violence and skin cutting) are the most prevalence and challenge phenomena among indigenous people of the region. Thus, this study was aimed at assessing on the effects of mal-traditional practices among indigenous people in State of Benishangul-Gumuz Region. In doing so, the study particularly attempted to examine the level (prevalence) and impact of these maltraditional practices on socio-economic and health conditions of indigenous people in study areas. To identify the factors hindering government officials in eliminating mal-traditional practices among the indigenous people in the region. The study was designed to be survey where quantitative and qualitative data were gathered through questionnaire. The questionnaire consists of both open-ended and close-ended items. Focus group discussions was made on the indigenous people to collect relevant information. Besides to these, an interview was made with experts and political appointees. Hence, 93 people were involved in the study in filling the questionnaire, 20 people interviewed and 90 people in FGD. Therefore, 203 people were totally the target groups of the study. Results of the study indicated that, the society had knowledge about the prevalence of harmful traditional practices. In the same manner, the society held a kind of favorable practice against MTP's although there remained many people in the society who still ignored and wanted to see their co-existence with the MTP's. As far as practice is concerned, it was found out that MTP's was exercised in their respective areas among indigenous communities, by a large number of people, for diverse reasons(social, economic, cultural cases). Eventually, based on the data interpreted and analyzed, conclusions are made, and recommendations are forwarded.
\end{abstract}

Keywords: Mal-traditional practices (MTP's), prevalence, Practices, marriages, festivities, State of Benishangul Gumuz region.

DOI: $10.7176 /$ RHSS/9-3-01

\section{Introduction}

Ethiopia today, with over 90 million people, the third largest country in Africa, has a great number of ethnic groups, whose cultures are as rich and varied as their composition. Consequently, Ethiopia has ample traditional practices to offer to the other parts of the country. The traditions have deep historical roots. The respect for traditions have been considered as one of the dominant characteristics of Ethiopians (Amare Dejene\& Aster Birhanselase, 2006:10). Despite of this fact, by mal-traditional practices, we mean all practices done deliberately by human being on the body or the consciousness of other human beings for no beneficial purpose, but rather for cultural or socioconventional intentions and which have harmful consequences on the health and the rights of the victims. As such, these practices have negative impacts often permanently on the life of the girl, the boys, the women, the children, the mother, the husband or their family members; it is therefore, a societal phenomenon (Morissand Akouyaté, May 2009:1)

On the other hand, some traditional practices such as early marriage, Abduction, Exchange Marriage, Festivals, Bride-wealth payment, Inheritance marriage, Funerals, Domestic violence, skin cutting practices and others have the effect of jeopardizing the health of the population and interfere with human rights of the individual who conforms to the practice. These should be dealt with and eradicated from the country in general and state of Benishangul Gumuz region in particular. However, every culture has its ways of valuing women, children, girls and boys, and assigns different patterns of behaviors, attitudes, roles, rights, responsibilities and expectations in the socialization process (Awoke Bayehetail, 2015). So this is the case for prevalent of mal-traditional practices among indigenous people in the State of Benishangul-Gumuz region. These indigenous people of the region have 
various types of mal-traditional practices which they experienced in their daily life. Thus, the mal-traditional practices such as Early marriage, Abduction, Exchange Marriage, Festivals, Bride wealth payment, Inheritance marriage, Funerals, Domestic violence, skin cutting practices and others are reflected within the family and community at large(Abebe Ano: 2010).

Researchers like Awoke Bayeh etail (2015) have studied on mal-traditional practices, giving attention on the level of the society's knowledge of traditional practices, the causes that contribute for the occurrence of maltraditional Practice, its prevalence and attitude of the community towards the practices in Amara region. Additionally, Kalkidan Bekele (2007) has conducted study on cultural practices that affected the status of women in Benishangul Gumuz Madura Woreda with specific emphasis on gender relation and gender based division of labor, right of women in the making and use of resources and participation of women in the decision making. But, these previous studies lacked in depth consideration of festivals, marriage related practices such as early marriage, inheritance marriage, exchange marriage, polygamy, and abduction) domestic violence and skin cutting practices which are widely practiced in the region. In conclusion, a comprehensive study of mal-traditional practices among indigenous people in State of Benishangul-Gumuz Region has not yet been thoroughly studied. Hence, the major purpose of this research is to investigate the long period unexplored malt-traditional practices of indigenous people of the region.

Hence, the very objectives of this study was to examine the level (prevalence) of mal-traditional practices (festivals, marriage related practices, domestic violence and skin cutting) among indigenous people of the region and to explore the effects of these mal-traditional practice son socio-economic and health conditions of indigenous people in study area.

This study was conducted within three (3) zones of Benishangul-Gumuz Regional state but it was undertaken only within 7 sampled Woredas. Although there are different MTPs (Mal-traditional Practices) practiced in the Benishangul Gumuz region, the study focused on commonly known and practiced ones that include, festivals, marriage related practices (early marriage, Abduction, Bride wealth Payment, Inheritance Marriage), domestic violence and skin cutting.

\section{Research Design and Methodology}

\subsection{The Study Area}

Benishangul-Gumuz Regional State (BGRS) is one of the nine Federal Regions of Ethiopia situated in north western part of the country. It shares boundaries in the northern and north eastern with Amhara region, in the east with Oromia region, in the south with Gambella region and in the west with Republic of Sudan (BenishangulGumuz Regional State Revised constitution, 2002).

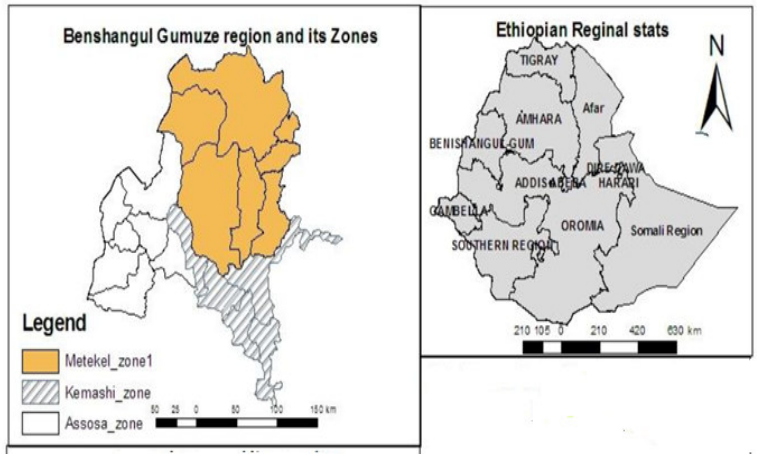

\subsection{The People in the Study Area}

There are five indigenous people living in state of Benishangul-Gumuz region. These are Gumuz, Shinasha, Berta, Mao and Komo. Linguistically, each has their own classes. Gumuz people belong to the Nilo-Saharan language family; according to Taddase Tamarat, they are among the earliest inhabitants of the Metekkel and originally occupied extensive territory that extended to the shores of Lake Tana and the Abbay basin. At present most of these people are living in the hot low-lands of Metekkel, Metemma and surrounding areas and Kamashi zone. Agriculture is the main occupation of the society and an individual can farm as much land as he can inside the territory of the clan. The Archaic agricultural tools and the size of labor that he receives during the working seasons limited his /her work not to plough and possess more than two hectares. The society cultivates many kinds of crops-sorghum, corn, millet; groundnut, cotton, tobacco and pumpkins are the most important. Fishing, hunting and gathering are also additional economic activities. But, the society does not own large livestock. The Gumuz people are also known for their honey production (Abebe: 2010:3)

The Shinasha are also one of the indigenous people, who live in region and have different cultural, economic 
and social practices that distinct them from others. The main economic activity of the Shinasha people is agriculture. They produce crops-sorghum, millet, corn, pumpkins, cotton and others. They reared various animals -cattle, to satisfy their need of food items. A small number of the society engages on hunting and gathering fruits and roots (Abebe: 2010:8). According to oral traditions of the society, the Shinasha people were one of the early settlers of the region. They have had their own language, which is called Borenona'a. Borenona'a literally it meant the Shinasha language and it is spoken in most parts of the region (ibid).

Berta, the indigenous people in the region belongs to the Nilotic language family. According to local traditions, the Berta occupy overwhelming territory that extended to Eastern Sennar in Sudan, south of Abbay River, Assosa zone and surrounding areas of the region. Agriculture, trade in gold, hunting and collection of wild fruits and seeds are the basis for economic activity of the people (History and Culture of the Benishangul Gumuz People: A paper presented on the $9^{\text {th }}$ Nations, Nationalities and People Day: August, 2007).

Komo is also an indigenous people in the region and according to traditions of the people; they occupy much extensive territory that extended from Mountain of Bagiewa or Gawi to Horro District of Komi as far as Border of Sudan in West and district of Tongo and some Districts of Gambella Regional State. The economic activity of the Komo people is Agriculture (Ibid).

Finally, Mao is also an indigenous people in the region and according to local tradition, they occupied large areas extended to Border of Sudan in west, Oromia region of Anfilo, Kundala, Begie, Nejo, Mensibu, Daddessa, Metahara and Southern Nation, Nationalities and people region of Bonga areas and the surroundings and within the region particularly Mao and Komo Special district (Woreda) and Bambasi district and Bello-jengafo district. The economic basis of Mao people is agriculture and hunting (Ibid).

\section{Methodology}

In order to achieve the general and specific objectives of the study, mixed research approach was employed. The fundamental principle of mixed method in conducting research was that multiple kinds of data collected was with different strategies and ways that reflecting complementary strengths and non-overlapping weaknesses (Johnson and Turner 2003).Hence data was collected in seven Woredas sample areas of the targeted populationgovernmental offices and residents of the Woredas who have different background and experience through selfadministered questionnaire, semi- structured interviews. Thus, information collected in these manners was supported by focus group discussions and secondary data. Therefore, this study appeared or resulted from both qualitative and quantitative approaches.

\subsection{Sampling Techniques}

purposive sampling was used in line with focusing with the title of the study and sample areas where the so called indigenous people were living in the region.

\subsection{Sampling Woredas}

In Benishangul-Gumuz Region there are three zones and one special Woreda, namely Metekel Zone, Kamashi, Assosa and Tongo Special Woreda consisting seven, five, seven and 1 Woredas respectively. In Metekel Zone; Dangur, Debati and Bullen Woredas were purposely selected for the reason that Shinasha and Gumuz people reside there for centuries. In Kamashi Zone, Kamashi and Yaso Woredas were sample areas; because Gumuz people confined in these areas of the zone. In Assosa zone, Homosha and Bambassi were selected for the reason that Berta people are reside in these sites. In addition, Tongo special Woreda was selected where Mao and Komo people are to live.

\subsection{Methods: Data Collection Instruments}

The main instruments that the researchers used for data collecting purpose were questionnaire, interview and focus group discussion (FGD). Besides, Primary data was supported by analyzing secondary documents that were obtained from different offices in the region.

\section{Result Discussion and Data analysis}

In this section, data collected on malt-traditional practices were presented, analyzed and also integratedily shown in the eyes of scholars' perspectives. The section dealt with more of qualitative data which comprised information obtained through questionnaire in open-ended questions, interview, and FGD about the types of mal-traditional practices, the effects of harmful traditional practices and dealt with government policy implications. Each of the harmful traditional practices, i.e. Festivals, Marriage related practices (Early Marriage, Abduction marriage, Inheritance marriage, Bride wealth payment), Domestic violence, and Skin cutting practices, were discussed from the angles of society's knowledge gap and practice as well as level of prevalence. Nevertheless, the data which was obtained through questionnaire was analyzed quantitatively by using a simple mathematical expressions and integrated with data analyzed qualitatively. 


\begin{tabular}{|c|c|c|c|}
\hline The traditional practices, festivals related occur(How often) & Frequency & Percent & Median \\
\hline Very Low & 14 & $15.1 \%$ & \multirow[t]{5}{*}{3.0000} \\
\hline Low & 16 & $17.2 \%$ & \\
\hline High & 39 & $41.9 \%$ & \\
\hline Very High & 24 & $25.8 \%$ & \\
\hline Total & 93 & $100.0 \%$ & \\
\hline
\end{tabular}

Table 1: Practice and Frequency of festivals in the region

The table displays that the data about the frequency of traditional practices, which were related with festivals and practiced among society. Then, $41.9 \%$ and $25.8 \%$ of respondents respectively responded that as there was high and very high practice of mal-traditions which were festival related.

\begin{tabular}{|l|l|l|l|}
\hline The traditional practices related with early marriage occur(How often) & Frequency & Percent & Median \\
\hline Very Low & 22 & $23.7 \%$ & 2.0000 \\
\hline Low & 33 & $35.5 \%$ \\
\hline High & 27 & $29.0 \%$ \\
\hline Very High & 11 & $11.8 \%$ \\
\hline Total & 93 & $100.0 \%$ & \\
\hline
\end{tabular}

Table 2: The practice and frequency of early marriage in the region

The above table depicts that 35.5 . \% and $23.7 \%$ of the respondents' data and the extent of early marriage becoming low and very low respectively in the region.

\begin{tabular}{|l|l|l|l|}
\hline The traditional practices- abduction related marriage occur(How often) & Frequency & Percent & Median \\
\hline Very Low & 42 & $45.2 \%$ & 2.0000 \\
\hline Low & 24 & $25.8 \%$ \\
\hline High & 16 & $17.2 \%$ \\
\hline very High & 11 & $11.8 \%$ \\
\hline Total & 93 & $100.0 \%$ & \\
\hline
\end{tabular}

\section{Table 3: The practice and frequency of abduction marriage in the region}

One can see that the practice and frequency of abduction marriage is becoming very low. Hence, it is possible in looking in to the data which tells us $45.2 \%$ and $25.8 \%$ of the respondents reaction portrays that its practice among the indigenous society is rated as low and very low respectively.

\begin{tabular}{|l|l|l|l|}
\hline The traditional practices related inheritance marriage occur (How often)? & Frequency & Percent & Median \\
\hline Very Low & 35 & $37.6 \%$ & 2.0000 \\
\hline Low & 31 & $33.3 \%$ & \\
\hline High & 14 & $15.1 \%$ \\
\hline very High & 13 & $14.0 \%$ \\
\hline Total & 93 & $100.0 \%$ & \\
\hline
\end{tabular}

\section{Table 4: Practice and frequency of inheritance Marriage in the region}

Accordingly, $37.6 \%$ and $33.3 \%$ respondents' data revealed that inheritance marriage is very low and low respectively practiced among the indigenous society in the region.

\begin{tabular}{|l|l|l|l|}
\hline $\begin{array}{l}\text { The traditional practices related with Bride wealth payment marriage } \\
\text { occur(How often) }\end{array}$ & Frequency & Percent & Median \\
\hline Very Low & 17 & 18.3 & 3.0000 \\
\hline Low & 19 & 20.4 \\
\hline High & 26 & 28.0 \\
\hline very High & 31 & 33.3 \\
\hline Total & 93 & 100.0 & \\
\hline
\end{tabular}

Table 5: The practice and frequency Bride wealth payment in the region.

The data reveals that the bride wealth payment was very in the region. That is $28 \%$ and $33.3 \%$ of the respondents' answer show that the practice is very high in the region. 


\begin{tabular}{|c|c|c|c|c|c|c|c|}
\hline No & Items & In Number & Transaction & Total & Unit & Transaction & Remark \\
\hline 1 & Oxen & 2 & $2 * 15,000$ & $30,000.00$ & & & \\
\hline 2 & Goats & 5 & $5 * 1200$ & $6,000.00$ & & & \\
\hline 3 & Sheep & 5 & $5 * 1300$ & $6,500.00$ & & & \\
\hline 4 & Cock & 5 & $5 * 150$ & 750.00 & & & \\
\hline 5 & Soft Drink & Two boxes & $2 * 241$ & 482.00 & & & \\
\hline 6 & Bear & Two boxes & $2 * 336$ & 672.00 & & & \\
\hline 7 & Oil & & & & 5liter & $5 * 27=135.00$ & \\
\hline 8 & Sugar & & & & 5kilo & $5 * 20=100.00$ & \\
\hline 8 & Alcohol(ouzo) & Two bottle & & & 5kilo & $5 * 50=125.00$ & \\
\hline 9 & Butter & & & & 5kilo & $5 * 80=400.00$ & \\
\hline \multicolumn{4}{|c|}{ Total } & $44,154.00$ & & 760.00 & \\
\hline
\end{tabular}

\section{Table 7. Bride Wealth Payment in Kamashi and Yaso Woreda}

Hence, one could easily understand the severity of the problem based on the data depicted on the above table. Following this, due to high wage paid to the girl's family the two beloved couple would not marry each other. The poor Gumuz young boy who could not offer this huge wage payment to the girl's father or mother could not marry his beloved wife. On the other hand, the girl could not have her beloved husband and her last fate is being prostitution, which was not ever, never experienced and practiced in Gumuz society. According to Gemeda, who is second year student in department of Language and literature in Assosa University, the current bride wealth payment in cash, alcohol and sugar form in Gumuz society specially in Kamashi zone did not display the exact culture of the Gumuz society.

\begin{tabular}{|l|l|l|l|}
\hline & Frequency & Percent & Median \\
\hline Very Low & 15 & $16.1 \%$ & 3.0000 \\
\hline Low & 20 & $21.5 \%$ & \\
\hline High & 34 & $36.6 \%$ & \\
\hline Very High & 24 & $25.8 \%$ & \\
\hline Total & 93 & $100.0 \%$ & \\
\hline
\end{tabular}

Table 8: The practice and frequency of Domestic Violence in the region

As one can see from table $6,36.6 \%$ and $25.8 \%$ respondents respectively replied that there was high and very high practice of domestic violence on women and girls among the society.

\begin{tabular}{|l|l|l|l|}
\hline The traditional practices related skin cutting occur(How often) & Frequency & Percent & Median \\
\hline Very Low & 37 & $39.8 \%$ & 2.0000 \\
\hline Low & 24 & $25.8 \%$ & \\
\hline High & 16 & $17.2 \%$ \\
\hline very High & 16 & $17.2 \%$ \\
\hline Total & 93 & $100.0 \%$ & \\
\hline
\end{tabular}

Table 9: The practice and frequency of skin cutting in the region

The study reveals that $39.8 \%$ and $25.8 \%$ the respondents answer show that skin cutting trading is becoming decreased in the region.

\section{Conclusions}

Based on the data analysis made in the previous chapters, the following points are derived as the major findings lead to conclusions. The level of prevalence of mal-traditional practices such as festivals, marriage related practices, early marriage, abduction marriage, inheritance marriage, bride wealth payment and domestic violence against women and girls and skin cutting were the harmful practices internalized among indigenous people of the region for long time.

- The extent of festival was highly practiced among the indigenous society in the region.

- The extent of early marriage at its outset was low practice and has come decreased, it was practiced rarely at the peripheral areas of the region

- Abduction marriage was in very low practice despite the fact that some data shows as there was some attempts (Practices) in Kebele's which are remote from the centers of each zones.

- Inheritance marriage was with low and very low practice in the region .It was reduced by the awareness creation program in connection was sexually Transmitted Disease(HIV \&Related diseases) given either by the experts or some political delegates. But, insignificant degree of the data show that as there was inheritance marriage practices in peripheral areas of the region.

- The extent of bride wealth payment was in very high practice on the indigenous people of the region, more particular in the Gumuz, Shinasha and Berta society. 
- Domestic violence practice against women and girls were very high among the indigenous society (Relatively high in Gumuz woman).

- Skin cutting was practiced to some extent in the region, but recently the study reveals that the practice has decreased with very low practice in the society.

- The impact of mal-traditional practices-Festivals, Marriage related practices such as Early marriage, Abduction marriage, and Inheritance marriage, Domestic violence against women and girls as well as Skin cutting were highly realized and affected the socio-economic and health condition of the community.

- It was found out that there existed opposite interrelation between knowledge gaps, and level of practice on MTP's and the effect of loss of government policy implementations. In connection with this, the study comes up with knowledge gap challenge and level of practice affects the socio-economic and health aspects of the indigenous people in the region.

In general, the indigenous people of the region are with mal-traditional practice -bride wealth marriage though others were showing positive progress. Generally, it could be concluded as there are mal-traditional practices on areas where indigenous groups live in the region. From the above writing one could generalize it as in Gumuz areas more particularly in Kamashi zone, there was high wage for bride wealth payment which advocates and paves ways to abduction marriage and exposing the youths for prostitution. Economically, the brides are becoming extravagant users of the money that they already owned sagaciously.

\section{Recommendations}

Based on the key-findings, the following points of recommendation have been forwarded. The regional government should employ new strategies that can help reduce the degree of prevalence of MTPs. For instance, the government should encourage community conversation to reinforce and improve the society's level of understanding further and thereby to reduce the likelihood of prevalence of MTP's. It should be underlined that there ought to be an intervention mechanism that can improve the situations of MTP's in Benishangul Gumuz region. Project has to be designed more particularly on the Peripheral rural kebele to eliminate mal-traditional practices. Intensive training needs to be organized. Laws should be practiced for those who breached it. Thus, regional government need to prepare umbrella that governs the violators.

The Benishangul Gumuz Region Gender Affairs, Government policy makers, Non- governmental organizations and other stakeholders should have great commitment in expelling ma-traditional practices among the society and propel only traditions that favors these people. This study indicated that the society's socioeconomic and cultural factors and multifarious other factors contributed a lot to the prevalence of MTP's. Therefore, remedial works should be made on each of the factors that might push the society to practice. Thus, it is alluded from the analysis that if these factors are avoided or reduced, it is likely that the practice of MTP's can be reduced greatly. As a long run strategies, the regional government should apply family and school based strategies to drain MTP's in particular and gender inequality in general from the grass roots.

\section{References}

AbebeAno(2010). The Shinasha of Metekkel: Northwestern Ethiopia: A Historical Survey to 1974.

Amare Dejene\& Aster Birhanselase(2006): Baseline Survey on Female Genital Mutilation and other Maltraditional Practice, in North Gondar Amhara Regional State.

AtnafuMorka(2009): Decentralization and Town Development in Benishangul-Gumuz Regional State.

Awoke Bayehetail (2015):The Status of Society's Knowledge, Attitude and Practice of Mal-traditional Practice: The Case of Amhara Regional State, Ethiopia; bureau of women, children and youths' affairs.

Drmorissandakouyaté (2009):Mal-traditional Practice against women and legislation.

Facts About Benishangul Gumuz Region (2007): Culture and truism of Benishangul GumuzRegion.

History and Culture of the Benishangul Gumuz People: A paper presented on the 9th Nations, Nationalities and People Day: August: 2007.

Johnson, R. B., \& Turner, L. A. (2003): Data collection strategies in mixed methods research. In A. Tashakkori\& C. Teddlie (Eds.), Handbook of mixed methods in social and behavioral research (pp. 297-319). Thousand Oaks, CA: Sage.

KahsuGebrekiros, MesfinAbebe and AtseduFentahun (2013):Across sectional study on factors associated with Mal-traditional Practice among children less than 5 years in Axum town, north Ethiopia.

KalkidanBekele (2007): cultural practices that affected the status of women in BenishangulGumuzMandura Woreda.

Koshy,V.(2005): Action Research Planner. Geelong, Victoria. Deaking University Press.

MFED (2012): Progress in abandoning female genital mutilation / cutting and child marriage in self-declared Woredas.

Paul J. Lavrakas(2008):Encyclopedia of SurveyResearch Methods; vol.1and 2

Selinger, H.W., and E.Showhamy (1989): Second language Research Methods .Oxford:-Oxford university press. 
History and Culture of the Benishangul Gumuz People: A paper presented on the 9th Nations, Nationalities and People Day: August: 2007.

The National Committee on Traditional Practices in Ethiopia (NCTPE) 2001.

WAO, 1992 E.C. A Survey Study on "Early Marriage" in Amhara National Region.

Women's Affairs Office, Amhara National Regional State, BahirDar. (Unpublished Amharic Document).

The Advocates for Human Rights (2010): Types\& Prevalence of Harmful Traditional Practices.

Convention on the Elimination of All forms of Discrimination againstWomen (CEDW) 1979; Harmful Traditional Practices Affecting the Health of Women andChildren; Fact Sheet No.23

United Nations Division for the Advancement of Women United Nations Economic Commission for Africa: 2009: Harmful traditional practices against women and legislation:

Adeyi, A, Adoga and Tonga L. Nimkur (2011). The traditional Amputated Uvula amongst Nigerians: still an ongoing practice. ISRN Otolaryngology 2011, http://dx.doi.org/105402/2011/704924. Assessed August 9, 2013.

Amare Dejene and Aster Birhanerselase(2006). Baseline Survey on Female Genital Mutilation and other Harmful Traditional Practices, in North Gondar Amhara Regional State. Addis Ababa: Save the Children Norway Ethiopia (SCNE).

BirhanRaswork. (2006).The impact of harmful traditional practices on the girl child. UNCIEF. Florence,Italy:Innocenti Research Centre.

Chia Longman \&TamsinBradley (2015). Interrogating Harmful Cultural Practices: Gender, Culture and Coercion London: Ashgate.

Committee on the Status of Women. (2007).Research report on glossary of violence against women. Geneva, Switzerland.

Central Statistical Authority Ethiopia. (2006). Ethiopia Demographic and Health Survey, 2005. CSA and ORC Macro.

Ethiopia Public Health Training Initiative (2005).Harmful Traditional Practices. Awassa: USAID.

Federal Democratic Republic of Ethiopia (FDRE). (1995). The Constitution of the Federal Democratic Republic of Ethiopia. Addis Ababa, Ethiopia.

Hobes,A.,D. \& Blank, J.,S. (2002). Sociology and the human experience. New York, John wiley and sons.

Kothari (2004). Research Methodology. New Age International (P) Ltd.

Lindner, M. (2008).The Social Dimension of Female Genital Cutting (FGC): The Case of Harari. Addis Ababa University, School of Graduate Studies, College of Social Sciences, Department of Sociology and Social Anthropology, Addis Ababa.

National Committee on Traditional Practice in Ethiopia (NCTPE). (2003). Old from imagining. Addis Ababa, Ethiopia.

National Committee on Traditional Practice in Ethiopia (NCTPE). (1999). Resource material on harmful traditional practices for policy makers. Addis Ababa, Ethiopia.

Ngunshi, R.B. (2011). Breast ironing: A harmful traditional practice in Cameroon.Cameroon.

Oxfam. (2005). Beyond the Mainstream: Education for Nomadic and Pastoralist Girls and Boys. Oxfam House. Retrieved from http://www.oxfam.org.uk/.

Shell-Duncan, B. (2008) 'From Health to Human Rights', American Anthropologist 1110.2: 225-36.

Southern Nation's, Nationalities and People's Region (SNNPR), Bureau of Statics and Population (BOFS). (2005). The study of Harmful Traditional Practices on demographic structure and socio-economic development in SNNPR. Addis Ababa, Ethiopia.

The Scuurpine, R. and Decorse, c. (2009). Anthropology a global perspective (6thed). New Delhi, India. PHI learning.

UNIFPA. (2006). In ending child marriage: A guide for global policy action International Planned Parenthood Federation and the Forum on Marriage and the Rights of Women and Girls. U.K.

United Nations Children's Fund (UNICEF) (2001). Early marriage: child spouses. Florence, Italy: Innocenti Research Centre.

United Nations Children's Fund (UNICEF). (2005). Early marriage: A harmful traditional practice. New York, USA.

United Nations Children's Fund (UNICEF). (2007). UNICEF's experience in the area of legislative reform: A review of Selected Countries. New York: UNICEF.

United Nations Children's Fund (UNICEF).(2006).The impact of harmful traditional practices on the girl child: Florence,Italy:Innocenti Research Centre.

United Nations Centre for Human Rights (UNCHR). (1995). Harmful Traditional Practices Affecting the Health of Women and Children. Geneva: Human Rights Fact Sheet, No.23 Retrieved from http://www.unhchr.ch/html/menu6/2/fs23.htm

United Nations (UN).(2009).Harmful Traditional Practices Against Women and Legislation. Addis Ababa, 
Ethiopia: United Nations Economic Commission for Africa.

World Health Organization (2010) 'Female Genital Mutilation', WHO Fact Sheet Number 241: February 2010, http://www.who.int/mediacentre/factsheets/fs241/en/

Women's International Network (2000). Community radio is a great way for women to communicate. Women's International Network of AMARC - Women Action.

Ye Ethiopia GojiLimadawiDirgitochAswogajMahiber (EGLDAM) (2008). Follow Up Survey On the Harmful Traditional Practices in Ethiopia. Addis Ababa, Ethiopia.

Ye Ethiopia GojiLimadawiDirgitochAswogajMahiber (EGLDAM) (2011).Follow Up Survey On the Harmful Traditional Practices in Ethiopia. Addis Ababa: Ethiopia. The former national committee for traditional practices of Ethiopia -NCTPE/ .AddisAbaba, Ethiopia. 